\title{
LOS ADOLESCENTES Y EL SISTEMA QUE LOS JUZGA. ASPECTOS Y MOTIVOS QUE LA LEY NO EXPLICA
}

\author{
ADOLESCENTS AND THE SYSTEM THAT JUDGES THEM. ASPECTS AND \\ REASONS WHICH THE LAW DOES NOT EXPLAIN
}

\author{
Gabriel Martínez-Cornelio ${ }^{1 *}$. \\ 1. Centro de Especialización Judicial del Poder Judicial de Tabasco, México. licmartinezgabriel@hotmail.com \\ * Autor de correspondencia: Gabriel Martínez Cornelio, correo electrónico: licmartinezgabriel@hotmail.com
}

\section{RESUMEN}

En este artículo se reflexiona sobre la evolución del sistema de juzgamiento para adolescentes en México y su relación con la teoría del desarrollo humano y la neurología; con la finalidad de conocer a qué se hace referencia cuando de adolescentes sujetos al sistema de justicia penal se habla. Un aspecto del principio de especialización que en la Ley, no se describe.

Palabras clave: Desarrollo; sistema de justicia penal.

\begin{abstract}
In this article we reflect on the evolution of the adolescents judging system in Mexico and its relationship with the human development theory in order to know what is being referred to when talking adolescents subject to the criminal justice system. A characteristic of the principle of specialisation which is not described in the law.
\end{abstract}

Keywords: Development; criminal justice system.

Cómo citar:

Martínez-Cornelio, Gabriel. (2021). Los adolescentes y el sistema que los juzga. Aspectos y motivos que la ley no explica. Revista de Investigaciones Universidad del Quindio, 33(S2),

132-146. https://doi.org/10.33975/riuq.vol33nS2.626

Revista de Investigaciones Universidad del Quindío, 


\section{INTRODUCCIÓN}

En diciembre de dos mil cinco, se reformó el artículo 18 de la Constitución Política de los Estados Unidos Mexicanos, instituyendo ahora que, la Federación, los Estados y el Distrito Federal, dentro del ámbito de sus competencias, establecerían respectivamente, el Sistema Integral de Justicia para Adolescentes; transitándose así, de un sistema tutelar en el que el adolescente era percibido como incapaz y que, por lo tanto, no necesitaba ser escuchado sino que, el Estado, debía brindar la tutela y protección necesaria a un sistema de justicia penal en el que se les reconoce como sujetos, con los mismos derechos de los adultos, más aquellos derivados de la condición de ser personas en desarrollo; pero, también, como capaces de responder penalmente por sus conductas.

Dicho sistema, si bien nace como resultado del compromiso adquirido por México en junio de 1990, al haber ratificado La Convención Internacional sobre los Derechos del Niño; constituye una respuesta al constante incremento de la participación de menores de edad en conductas que impactan a la sociedad, como homicidios, secuestros, delincuencia organizada, violación entre otros.

Esto, porque ahora a los adolescentes se les instruye un proceso penal en el que se debe vencer la presunción de inocencia para ser declarados culpables por la comisión de un delito; empero, matizado por disposiciones especiales determinadas por la peculiaridad de su desarrollo.

Ahora, las conductas cometidas por adolescentes ya no se sancionan por la autoridad administrativa; sino por el Poder Judicial, que los juzga y en su caso, los declara responsables de la comisión de delitos y procede a imponer en los casos más graves el internamiento.

Sin embargo, esto implica que los operadores de ambos sistemas, no sólo sean personas diferentes, sino que posean distintos conocimientos y experiencias.

Los primeros habituados a tratar con niños en abandono o en situación irregular y los segundos con adultos desde una perspectiva penal, que ahora han de aplicar un proceso para adolescentes con analogía con el de los adultos; empero, regido por principios que en el sistema para mayores de edad no estaban presentes como el de especialidad y el del interés superior del niño, los que se consideran pilares de la justicia para adolescentes.

Este gran cambio, propició la actualización de los operadores de las distintas fases que comprenden el sistema; empero, focalizado en el marco jurídico y con desdén se abordó la relación que el proceso biológico que se gesta en el cuerpo de una persona en desarrollo tiene con el procedimiento penal instruido a los adolescentes, lo que resulta fundamental para reintegrarles a la sociedad y la familia; pero, ¿cómo realizar tan ardua tarea si se les trata como adultos pequeños?

Es en este tema en el que se centra la investigación, a través de la cual, desde un punto de vista jurídico y desde la neurología y la teoría del desarrollo humano, se explicará la peculiaridad del sujeto activo del sistema de justicia penal para adolescentes y su relación con la finalidad del sistema; para lo cual, es necesario primero contextualizar el trato que este grupo de personas ha recibido a través del tiempo. 


\section{Las diferentes perspectivas desde las que se ha abordado jurídicamente la conducta disocial en México.}

"La historia, émula del tiempo, depósito de las acciones, testigo del pasado, ejemplo y aviso del presente, advertencia del porvenir” Miguel de Cervantes Saavedra.

Conocer los enfoques que han servido de base para el trato de la conducta con rasgos disóciales, resulta fundamental para entender el presente y advertir el porvenir de la justicia para adolescentes en México, pues lo que en su momento constituyó el paradigma jurídico, en el presente, revela el costo de la experiencia y lo que no se debe repetir; empero, también de lo que se debe aprender, conciliar o retomar para materializar la nueva perspectiva al trato de la conducta con rasgos disóciales; por lo tanto, al ser el presente un análisis jurídico, resulta útil acudir al Código Penal de 1871, para el Distrito Federal y Territorio de Baja California, sobre delitos del fuero común y para toda la República Mexicana, sobre delitos contra la federación, también conocido como el Código de Martínez de Castro.

\section{Perspectiva Penal.}

Dicho ordenamiento se caracterizó por adoptar la teoría clásica del delito, que justificaba el derecho de reprimirlo a partir del libre albedrío del sujeto para elegir entre el bien y el mal, de este modo se justificaba un sistema diferenciado en el trato de las conductas típicas cometidas por personas menores de edad a partir de reconocer su insuficiente evolución mental -factor biológico- para comprender la trascendencia de su conducta, es decir, para optar por el bien en vez del mal, por lo cual se consideraba que se asemejaban a los "locos y sordomudos".

Siendo así, dicho código establecía en el discernimiento y la edad las bases para definir la responsabilidad de las personas menores de edad, tal como lo preveían sus artículos $32^{1}$ y $34^{2}$, que establecían el presupuesto para que, todas las personas a partir de los nueve años de edad, quedaran comprendidas dentro del ámbito de validez personal de aplicación de la norma penal.

Sin embargo, de los nueve a menos de catorce años estaban sujetos a que el acusador demostrare que, habían actuado con discernimiento, lo que se determinaba a través de un dictamen pericial; ${ }^{3}$ de los catorce años en adelante se les consideraba con responsabilidad criminal o imputables; no obstante, con la posibilidad de que la sanción se atenuara. ${ }^{4}$

Por lo tanto, los menores de nueve años y los de nueve pero menores de catorce años, respecto de los cuales el acusador no hubiese demostrado que habían actuado con discernimiento, el Código de Martínez de Castro, instituía que quedaban exentos de responsabilidad criminal, por ende los sustraía del derecho penal y de los efectos de la pena. ${ }^{5}$

1 Todo delito produce responsabilidad criminal, esto es, sujeta a una pena al que lo comete, aunque sólo haya tenido culpa y no dañada intención.

2 Las circunstancias que excluyen la responsabilidad criminal por la infracción de leyes penales son: ... $5^{\mathrm{a}}$. Ser menor de nueve años. $6^{\text {a }}$. Ser mayor de nueve y menor de catorce al cometer el delito, si el acusador no probare que el acusado obró con discernimiento necesario para conocer la ilicitud de la infracción...

3 Estudio Histórico y Comparado de la Legislación de Menores Infractores, análisis de Celia Blanco Escandón, disponible en http://biblio.juridicas.unam.mx/libros/4/1968/7.pdf

4 Artículo 42 fracción II, del citado ordenamiento penal: "Son atenuantes de cuarta clase: II. Ser el acusado decrépito, menor o sordomudo, sino se tiene el discernimiento necesario para conocer toda la ilicitud de la infracción"

5 Artículo 32. Todo delito produce responsabilidad criminal, esto es, sujeta á una pena al que lo comete, aunque solo haya tenido culpa y no dañada intención. 
Siendo así, una vez que se establecía que, las personas de nueve años y menores de catorce que hubiesen actuado con discernimiento y las de catorce y menos de dieciocho, eran consideradas con responsabilidad criminal y por lo tanto, sometidas al proceso en el que se determinara si habían cometido algún delito. ${ }^{6}$

Es importante señalar que, este Código, establecía que, las personas que tuvieran que estar en reclusión preventiva o prisión, lo hicieran en lugares diferentes tomando como parámetro para ello la edad y el discernimiento, aquéllas menores de nueve años y aquéllas de nueve pero menores de catorce años, que hubiesen infringido una ley penal sin discernimiento debían ser recluidas en un centro de educación correccional; en tanto que, las personas de nueve años pero menores de dieciocho, que hubiesen delinquido con discernimiento debían hacerlo en un centro de corrección penal y las personas mayores de esa edad en un centro de prisión ordinaria. ${ }^{7}$

Sin embargo, aunque se reconocía la importancia de separar a los menores de dieciocho años que habían cometido algún delito de los mayores de edad, no se contaba con la infraestructura para llevar a cabo tal intención.

Por lo que las personas de catorce años en adelante eran enviadas a cárceles para adultos, lo cual como es fácil inferir, sometía a personas vulnerables a las influencias negativas y abusos por parte de los reos adultos.

Según Clavijero Francisco Javier: ${ }^{8}$

En 1908 se trasladó a Tlalpan la Escuela Correccional que estaba ubicada en el ex convento de San Pedro y San Pablo. En estas escuelas correccionales se segregó a los menores que, tras haber cometido un delito, o por su situación de "pobres", requerían el apoyo del gobierno; sin embargo, en las cárceles existían menores privados de su libertad. Así lo relata Ríos: “...la antigua cárcel de Belem, cloaca inmunda (...) era albergue de adultos y menores en promiscuidad repugnante, y sufriendo los menores las consecuencias que causaron piedad hasta a los duros y ásperos celadores (...) quienes tal vez proyectando en esos niños encarcelados la imagen de sus hijos, tuvieron un sentimiento de piedad y los segregaron de los adultos, dedicándoles una crujía especial y para que se diferenciaran del grupo de población les pusieron un uniforme verde, y fue por esto que se llamó la crujía de los pericos".

6Artículo. 224. Siempre que se declare que el acusado mayor de nueve años y menor de catorce delinquió con discernimiento, se le condenará a reclusión en establecimiento de corrección penal por un tiempo que no baje de la tercia parte, ni exceda de la mitad, del término que debiera durar la pena que se le impondría siendo mayor de edad. 225. Cuando el acusado sea mayor de catorce años y menor de diez y ocho, la reclusión será por un tiempo que no baje de la mitad, ni exceda de los dos tercios de la pena que se le impondría siendo mayor de edad.

7 Artículo 160. Ni los jueces ni las autoridades gubernativas podrán poner en el establecimiento de educación correccional, ni serán admitidos en él jóvenes condenados por haber delinquido con discernimiento... Reclusión en establecimiento de corrección penal. art. 127. La reclusión de esta clase se hará efectiva en un establecimiento de corrección, destinado exclusivamente para la represión de jóvenes mayores de nueve años y menores de diez y ocho, que hayan delinquido con discernimiento. En dicho establecimiento no sólo sufrirán su pena, sino que recibirán al mismo tiempo educación física y moral. ART. 128. Los jóvenes condenados a reclusión penal estarán en incomunicación absoluta al principio de su pena desde ocho hasta veinte días, según fuere la gravedad de su delito; pero pasado ese período trabajarán en común con los demás reclusos, a no ser que su conducta posterior haga de nuevo necesaria su incomunicación.

8 Clavijero, Francisco Javier, "Historia Antigua de México", Sepan cuantos, México, Porrúa, 1982, pp. 202, 203. justicia de_menores.pdf 
El principal contra argumento para esta perspectiva, lo representó el determinar "el discernimiento" sobre todo, los parámetros que incrementaban la vaguedad, tales como, "discernimiento necesario" y "discernimiento insuficiente"

Por lo anterior se consideró ineficaz para tratar los problemas de criminalidad en niños, por lo que desde el punto de vista de los estudiosos de la infancia, se hizo imperante que se adoptara una nueva perspectiva para abordar la criminalidad de menores de edad.

Un cambio de obligada referencia por provenir del País vecino, Estados Unidos de Norte América, se suscitó en 1899, con la creación de la corte juvenil especializada en el Estado de Illinois, por medio de la Juvenile Court Act de Illinois;9 ello, resultaba relevante porque constituía la instauración de Tribunales especializados, cuya idea central era que los jóvenes no podían ser penalmente responsables por los delitos que hubieren cometido y, por tanto, se buscaba la ayuda y rehabilitación de los jóvenes infractores. 10

Así, los trabajos del Juez Norte Americano Eduard Hubert Julhiet, -precursor de este nuevo modelopara promover un sistema de justicia de menores separados de los adultos, concluyeron en la celebración del primer congreso internacional de Tribunales de menores en 1911, efectuado en París, Francia; del que derivó la siguiente perspectiva.

\section{El Tribunal de Menores.}

En México, la creación de un Tribunal para Menores se consolidó en 1928, con la expedición de la Ley sobre Previsión Social de la Delincuencia Infantil en el Distrito Federal, conocida como la Ley Villa Michel, de marzo del año en mención, en esta ley se establecía que los menores de quince años no tenían responsabilidad penal.

Una descripción de la aplicación de este sistema, a través de los Tribunales de Menores, la encontramos en la Tesis de La Primera Sala, “Tribunal para menores, naturaleza del."11

La cual sirve a los interés del presente trabajo, pues plasma la interpretación que la Primera Sala, daba a la finalidad del sistema en relación con las "garantías constitucionales"12 de los niños.

De la que podemos extraer los siguientes puntos:

1. Los Tribunales para menores se encontraban fuera del ámbito del derecho penal; por lo que, sólo atendían casos de infracciones a leyes penales y reglamentos gubernativos.

2. Toda persona menor de dieciocho años estaba exenta de responsabilidad criminal.

3. Las resoluciones de dicho Órgano, no tenían carácter de sentencias sino de medidas preventivas y

9 Cervantes Gómez, Juan Carlos, “Análisis de la legislación en materia de justicia para adolescentes”, Quórum legislativo, México, Centro de estudios de derecho e investigaciones parlamentarias, núm. 91, octubre - diciembre 2007. http://www3. diputados.gob.mx/camara/content/download/193563/464280/file/legislacion\%20adolescentes.pdf.

10 Gardner, Martin, Understanding Juvenile Law, New York: Mathew Bender, 1997, pp. 183, citado en: Duce, Mauricio y Couso, Jaime, "El derecho a un juzgamiento especializado de los jóvenes infractores en el derecho comparado". Polít. crim. Vol. 7, núm. 13 Julio de 2012, pp. 1 - 73. [http://www.politicacriminal.cl/Vol_07/n_13/Vol7N13A1.pdf

El Derecho a un Juzgamiento Especializado de los Jóvenes Infractores en el Derecho Comparado. Disponible en http:// www.politicacriminal.cl/Vol_07/n_13/Vol7N13A1.pdf

11 Tesis: Aislada con registro digital 311432, Semanario Judicial de la Federación y su Gaceta, Quinta Época, t. L, p. 1352 12 De acuerdo con la corriente vigente en esa Época. 
educadoras, dentro de las cuales se encontraban las de guarda de la persona y reclusión educacional.

4. Los policías y los jueces no tenían más intervención que, enviar a los menores al Tribunal competente.

5. Cualquiera que fuera la edad de los menores gozaban de las garantías compatibles con su minoridad, por lo cual no podían ser detenidos sin ajustarse a los artículos 16 y 19 de la Constitución.

6. Sin embargo, se precisó que el menor estaba sujeto a limitaciones en el goce de derechos inherentes a la personalidad; entre otros el de la libertad, restringido por quienes en ellos ejercían la patria potestad en cuyo ejercicio el Estado intervenía como auxiliar.

7. A los infractores, no se les internaba en la cárcel, sino que se les matriculaba en una casa de observación, donde el procedimiento tenía un carácter familiar y adecuado al mejor éxito de la observación científica.

8. De esta forma, al ser la intervención del Estado sólo en auxilio o sustitución de la patria potestad y no en su carácter de autoridad, no existía violación de garantías constitucionales y el amparo resultaba improcedente.

9. Instituyendo como excepción a la improcedencia del juicio de amparo la materialización del poder coactivo del Estado, lo cual ocurría cuando no se demostrare que respecto del menor faltare quien debiera ejercer la patria potestad, no pudiera ejercerla o no fuera capaz para ello.

Es importante destacar que la primera sala concluye que, si bien, el tribunal para menores sólo podía decretar en sus resoluciones, la aplicación de una medida tutelar y la clase de ella; el artículo 404 del Código Penal de aquélla época, establecía una excepción para el caso de que la infracción que se cometiera por un menor de dieciocho años, pero mayor de doce, fuera grave y que con ella se demostrara alguna temibilidad; entonces, se aplicaría la sanción correspondiente, con las atenuaciones que procedieran a juicio del tribunal.

Empero que, a pesar de la excepción no podía considerarse que el sistema adoptado por el Estado, para la corrección de los menores, hubiese cambiado porque su mismo carácter de excepción, afirmaba el sentido general de la reglamentación, en materia de delincuencia.

Lo anterior generó otros cuestionamientos como la falta de un defensor para los "menores infractores" y la falta de sustento constitucional de los Tribunales de Menores.

Es así que, en 1965, en el artículo 18 de la Constitución Mexicana, se instituyó: "La Federación y los gobiernos de los Estados establecerán instituciones especiales para el tratamiento de menores infractores".

Dicha reforma sustentó constitucionalmente al Tribunal de Menores; es hasta 1974, cuando se produce un cambio importante en el sistema que se analiza, pues en el año en mención se expidió la Ley que crea el Consejo Tutelar para Menores Infractores del Distrito Federal, con la cual quedó atrás el Tribunal para Menores. 13

De este modo inicia en México la aplicación del sistema a través de los Consejos Tutelares para Menores Infractores.

13 Artículo $1^{\circ}$ de la Ley en cita: "La presente Ley entrará en vigor a los treinta días de su publicación en el "Diario Oficial”, y a partir de la misma fecha quedarán derogados los artículos 119 a 122 del Código Penal para el Distrito y Territorios Federales en materia del Fuero Común y para toda la República en materia del Fuero Federal, de 13 de agosto de 1931, sólo por lo que se refiere al Distrito y Territorios Federales, la Ley Orgánica y Normas de procedimientos de los Tribunales de Menores y sus Instituciones Auxiliares en el Distrito y Territorios Federales, de 22 de abril de 1941 y las demás disposiciones que se opongan al presente Ordenamiento". 


\section{El Consejo Tutelar para menores infractores.}

Este órgano especializado, al igual que el Tribunal de Menores, descansaba en el sistema proteccionista, tutelar o de la situación irregular; es decir, la intervención del Estado, no era coactiva, sino en auxilio o sustitución de la patria potestad, por lo tanto, al menos en la época de su creación tampoco era considerado Autoridad para los efectos del Amparo.

El consejo, al igual que el Tribunal de Menores, seguía ocupándose no sólo de los menores de edad que habían cometido infracciones a las leyes penales o reglamentos gubernamentales, sino de aquellos en situación de riesgo o víctimas sociales como se desprende del artículo 2, de la Ley de la materia:

El Consejo Tutelar intervendrá, en los términos de la presente Ley, cuando los menores infrinjan las leyes penales o los reglamentos de policía y buen gobierno, o manifiesten otra forma de conducta que haga presumir, fundadamente, una inclinación a causar daños, así mismo, a su familia o a la sociedad, y ameriten, por lo tanto, la actuación preventiva del Consejo.

Incluso como en el caso de Tabasco, se ocupaba de los menores moralmente abandonados.

Tal como se ejemplifica en el artículo 1. De la abrogada Ley Orgánica y de Procedimientos del consejo tutelar para menores infractores del estado de Tabasco:

El consejo tutelar para menores con sede en la capital del estado, tiene por objeto promover la readaptación social de los menores de ocho hasta diecisiete años, que infrinjan las leyes penales o manifiesten una conducta nociva para ellos mismos, para su familia y para la sociedad, y procurará el aseguramiento de la educación, desarrollo y protección de los menores física y moralmente abandonados.

La apliación de dicho modelo en México, quedó atrás con la reforma de 2005, al artículo 18 Constitucional, lo que dio paso a la apliación del:

\section{Modelo de la protección integral de los derechos del niño.}

El sistema tutelar quedó atrás básicamente con la Convención de Naciones Unidas sobre los derechos del niño de 1989, ${ }^{14}$ cuyo instrumento vinculado a Las Reglas Mínimas de Las Naciones Unidas para la Administración de Justicia Juvenil (Reglas de Beijing). Las Reglas Mínimas de las Naciones Unidas para los Jóvenes Privados de la Libertad. Las Directrices de las Naciones Unidas para Prevenir la delincuencia Juvenil; constituyen el fundamento de la doctrina de la protección integral de los derechos del niño, ${ }^{15}$ termino con el cual se hace referencia a un conjunto de instrumentos jurídicos, de carácter internacional que expresan un salto cualitativo fundamental en la consideración social de la infancia. Reconociendo como antecedente directo la Declaración de los derechos del niño. ${ }^{16}$

Dicha doctrina concibe a los niños como sujetos de derecho pero también de obligaciones; por lo

14 Convención sobre los Derechos del Niño. Adoptada en Nueva York el 20 de noviembre de 1989. Entró en vigor el 2 de septiembre de 1990. Para México, publicado en el Diario Oficial de la Federación el 25 de enero de 1991.

15 Suprema Corte de Justicia de la Nación, La justicia de menores a la luz de los criterios del Poder Judicial de la Federación, México, SCJN, 2007. P. 224 y 225.

16 García Méndez, Emilio, Infancia y adolescencia; de los derechos y la justicia, Doctrina Jurídica Contemporánea, México, UNICEF, Fontamara, 2001, p. 29. 
tanto, el niño no sólo es titular de derechos que le deben ser reconocidos, respetados y garantizados, sino también es sujeto de obligaciones, deberes y responsabilidades, en este sentido, cuando comete una conducta tipificada como delito por la ley penal, se le debe atribuir una responsabilidad específica por ese hecho; pero respetando su derecho a expresarse, a defenderse, a exponer, a ser escuchado.

Por lo que, ya no se percibe a los niños como "menores", incapaces o personas en proceso de la adultez, sino, como personas cuya particularidad es estar creciendo, por eso, se le reconocen todos y cada uno de los derechos que tienen los adultos, más derechos específicos precisamente por esa circunstancia evolutiva, el derecho del niño a ser oído y a que sus opiniones sean tomadas en cuenta es fundamental y estructurante de la lógica de la protección integral.

Este cambio de paradigma es lo que se ha dado en llamar el modelo garantista. La doctrina garantista o de protección integral considera que el menor es titular de todas las garantías propias de los adultos, además de las complementarias especificas para los niños a fin de limitar las pretensiones punitivas del Estado, con lo cual el interés superior del niño dejó de ser una etérea consideración del bien del niño, pasando en cambio a ser equivalente a la plena satisfacción de sus derechos.17

Dicha teoría se materializó en México con la reforma de diciembre de dos mil cinco al artículo 18 de la Constitución Politica de los Estados Unidos Mexicanos. 18

Por virtud de la cual, en este modelo la administración de justicia se deposita en autoridades judiciales especializadas.

No obstante, el sistema no sólo se constituye por el proceso penal instruido a los adolescentes; sino que, se caracteriza por su integriad, la cual se deriva de la interdependencia de cada una de las fases que componen el sistema tal como lo especificó la Suprema Corte de Justicia de la Nación, en la jurisprudencia derivada de la acción de inconstitucionalidad 37/2006, Sistema integral de justicia para adolescentes. Facetas del problema de la delincuencia juvenil de las que deriva el carácter sistémico de la justicia juvenil.

En las Reglas de Beijing y en las Directrices de las Naciones Unidas para la Prevención de la Delincuencia Juvenil (Directrices de Riad), se hace referencia a las diversas facetas del problema de la delincuencia juvenil que quedan comprendidas en el aspecto sistémico a que alude la reforma al artículo 18 de la Constitución Política de los Estados Unidos Mexicanos de diciembre de 2005. ... Con base en lo anterior, puede afirmarse que el carácter sistémico de la justicia juvenil deriva de la comprensión de diversas facetas del problema de la delincuencia juvenil, que abarcan tanto aspectos de política social como de política judicial, criminal y de control de gestión, que pueden identificarse como: 1) prevención, 2) procuración de justicia, 3) impartición de justicia, 4) tratamiento o ejecución de la medida, y 5) investigación, planificación, formulación y evaluación

17 Cillero, Miguel, La responsabilidad Penal de Adolescentes y el interés del Niño: ¿complemento o contradicción? Argentina, Ediciones del Signo: Editores del Puerto, Buenos Aires, 2004, p.36.

18 Artículo 18, párrafo cuarto. La Federación, los Estados y el Distrito Federal establecerán, en el ámbito de sus respectivas competencias, un sistema integral de justicia que será aplicable a quienes se atribuya la realización de una conducta tipificada como delito por las leyes penales y tengan entre doce años cumplidos y menos de dieciocho años de edad, en el que se garanticen los derechos fundamentales que reconoce esta Constitución para todo individuo, así como aquellos derechos específicos que por su condición de personas en desarrollo les han sido reconocidos. Las personas menores de doce años que hayan realizado una conducta prevista como delito en la ley, solo serán sujetos a rehabilitación y asistencia social. 
de las políticas que incidan en la materia. ${ }^{19}$

Se sigue entonces a los adolescentes a quienes se les atribuye la ejecución de un delito, un juicio en el que se respetan todas las garantías procesales y sustantivas, hasta emitir una sentencia, en la que se debe de imponer una medida con base en las causas que la propiciarion y con la finalidad de la reintegración social y familiar.

\section{LA ADOLESCENCIA, UNA ETAPA INEVITABLE.}

Lo primero que debe decirse sobre la adolescencia es que, el adolescente no adolece.

La palabra adolescencia, proviene del verbo latino adoleceré, el cual significa crecer, desarrollarse; por lo tanto, el adolescente es el que está creciendo.20

Adolecer significa: Tener algún defecto o vicio, carecer de algo; padecer una enfermedad; tener alguien una cualidad negativa. ${ }^{21}$

La Organización Mundial de la Salud la define como: el perido de crecimiento y desarrollo humano que se produce despues de la niñez y antes de la edad adulta entre los 10 y los 19 años. Es la etapa de transcición más importante de la vida del ser humano, caracterizada por un ritmo acelerado de crecimiento y cambios, en el que el comienzo de la pubertad marca el pasaje de la niñez a la adolescencia.

La pubertad es el proceso que lleva a la madurez sexual o fertilidad, es decir, la capacidad para reproducirse; la cual tiene lugar antes de los 10 años.

Es decir, la pubertad aunque concurre con la adolescencia, desde una perspectiva biologica, está destinada a la maduración de los órganos reproductivos; en tanto, que la adolescencia encaminada al desarrollo emocional y mental en pos de la vida adulta.22

La adolescencia es una etapa en la que el cerebro experimenta un ciclo continuo de crecimiento y en la que a partir de aproximadamente los 11 años de edad, se produce una explosión de actividad eléctrica y fisiológica, que reorganiza drásticamente miles de millones de redes neuronales que afectan a las aptitudes emocionales y a las habilidades físicas y mentales. 23

Según Paul Thompson, Ph.D., Profesor Asistente de Neurología, UCLA School of Medicine:

De los 7 a 15 años, el crecimiento de los lóbulos temporales/parietales es intenso, los cuales se relacionan con el lenguaje, matemáticas. De los 16 a los 20 años, acontece la perdida del tejido

19 Tesis: P./J. 69/2008, Semanario Judicial de la Federación y su Gaceta, Novena época, t. XXVIII, Septiembre de 2008, p. 620

20 Diccionario etimológico en línea.

21 Multidiccionario de la lengua española ESPASA, Madrid. 2007.

22 Manes, Facundo y Niro, Mateo, Usar el cerebro, conocer nuestra mente para vivir mejor, 9a ed., Argentina, Paidos, 2014 , p. 224.

23 “La adolescencia una etapa fundamental” Fondo de las Naciones Unidas para la Infancia (UNICEF), Nueva York, 2002. http://www.unicef.org/spanish/publications/files/pub_adolescence_sp.pdf 
en los circuitos frontales, relacionados con el autocontrol, planificación, conducta regular. El córtex pre frontal (situado detrás de la frente) desarrolla nuevas e importantes funciones y no madura totalmente hasta la edad de 18 años. Actúa como comandante en jefe, responsable de la planificación, organización y juicio, encargado de resolver problemas y del control emocional. ...Los científicos creen que la época que media entre los 10 y los 20 años puede ser clave para ejercitar el cerebro y que los adolescentes que aprenden a poner en orden sus pensamientos, medir sus impulsos y pensar de forma abstracta pueden establecer bases neuronales importantes que perdurarán a lo largo de sus vidas. 24

Dicho de otro modo, cursar esta etapa de la vida significa el inicio de la transición de la infancia a la adultez; en esta etapa las niñas y los niños tienen nuevos cuerpos, genitales en crecimiento, un nuevo tono de voz, mayor estatura y fuerza, un gran incremento hormonal.

Son personas que de la noche a la mañana han adquirido el cuerpo de un adulto, por lo que, experimentar, buscar independencia, identidad, resulta algo inevitable.

En esta etapa de la vida los seres humanos aumentan la producción de la mielina que permite que los impulsos nerviosos viajen más rapido. ${ }^{25}$

Es como, tener todo lo necesario para llevar a cabo cualquiera actividad tal como un adulto lo haría; pero, sin la capacidad necesaria para ejercer juicio racional sobre las consecuencias de sus decisiones, por lo que, son propensos a tomarlas basadas en las emociones.

Pues, cabe recordar que, los lobulos frontales son la región del cerebro con funciones tan complejas como la capacidad para tomar desiciones, para inhibir respuestas inapropiadas, para planificar y ejecutar un plan de acción, para ponerse en el lugar del otro y para poder discernir qué pautas establece cada sociedad sobre lo que está bien y lo que está mal. ${ }^{26}$

En esta etapa, el pensamiento de las y los adolescentes es de las "Operaciones Formales", lo que significa que, saca conclusiones a partir de lo que está percibiendo de manera directa y posiblemente llegue a soluciones que resultan incoherentes desde el punto de vista de la lógica adulto. ${ }^{27}$

Empero, por si no fuesen suficientes, la revolución hormonal, los cambios corporales y los cambios mentales; el desarrollo no es un proceso exclusivamente biológico; sino que, todos los sucesos vividos, traumas, abusos, drogadicción, alcoholismo, podrían afectar de manera negativa el funcionamiento del cerebro. ${ }^{28}$

Pero no sólo eso; sino que, podrían determinar el comportamiento y el carácter del adulto en un sentido negativo.

24 Citado en "La adolescencia una etapa fundamental" Fondo de las Naciones Unidas para la Infancia (UNICEF), Nueva York, 2002. http://www.unicef.org/spanish/publications/files/pub_adolescence_sp.pdf

25 Op. Cit. Not. 23, p.226

26 Op.Cit. Not. 23, p., 224

27 Sistema Nacional para el Desarrollo de la Familia, "Protocolo para los profesionales de la niñez y adolescencia, en el primer acercamiento con niñas, niños y adolescentes en contextos de violencia familiar", Procuraduría Federal de Protección de Niñas, Niños y Adolescentes Dirección General de Normatividad, Promoción y Difusión de los Derechos de Niñas, Niños y Adolescentes. http://sitios1.dif.gob.mx/procuraduriaDIF/docs/Protocolo_para_profesionales_ninez.pdf 28 "La adolescencia una etapa fundamental" Fondo de las Naciones Unidas para la Infancia (UNICEF), Nueva York, 2002. Disponible en: http://www.unicef.org/spanish/publications/files/pub_adolescence_sp.pdf. 
Dado que, en la consolidación de las conexiones neuronales las experiencias juegan un papel preponderante para la regulación de las emociones, lo que es fundamental para la convivencia en sociedad; ya que, los seres humanos tenemos la capacidad de transformar la experiencia emocional al cambiar el significado que le otorgamos a la situación que da lugar a la respuesta emocional. ${ }^{29}$

Pudiera pensarse que a estos riesgos están expuestos tanto los adolescentes como los adultos; sin embargo los primeros enfrentan el riesgo en el camino de sus potencialidades y en el camino hacia su autonomía; en tanto que los segundos sólo en la búsqueda de sus objetivos.30

De acuerdo con las teorias del desarrollo.31 El desarrollo multidimencional implica:

Un proceso complejo, que comprende áreas capaces de ser delimitadas: desarrollo físico, cognoscitivo, emocional y social, y no obstante, al estar siempre en interconexión, no pueden ser analizadas por separado para inferir y concluir sobre el comportamiento.32

De modo que, como se anunciaba el desarrollo del adolescente no es sólo físico, cognositivo, emocional, sino que, también lo es social.

Desarrollo físico: Incluye las bases genéticas del desarrollo, el crecimiento físico de todos los componentes del cuerpo, cambios en el desarrollo motor, los sentidos y los sistemas corporales. Desarrollo cognitivo: Comprende los cambios en los procesos intelectuales del pensamiento, el aprendizaje, el recuerdo, los juicios, la solución de problemas, lenguaje y la comunicación, incluye influencias tanto hereditarias como ambientales en el proceso de desarrollo. Desarrollo emocional y psicoactivo: Infiere el desarrollo del apego, la confianza, la seguridad, el afecto y las emociones, el desarrollo del concepto de sí mismo y el grado de autonomía. Desarrollo social: Se centra en el desarrollo moral, adaptativo, interrelacional, vincular.

De acuerdo con el modelo constructivista:

El conocimiento se edifica en el interior del sujeto, a través de los dispositivos cognitivos con los que cuenta y los mecanismos que permiten transformaciones de esa misma realidad externa; por lo que la actuación del sujeto, la experiencia con situaciones y objetos, representan, no solo el mundo interno del sujeto, sino también cómo éste incide en el entorno. Así, el sujeto es una construcción propia que se va produciendo como resultado de la interacción entre estas dos variables.33

De modo que, como se adelantaba, en la adolescencia el ser humano no sólo crece; sino que, experimenta, interactúa y en esa medida conforme al manejo de sus vivencias incide en su entorno.

29 Op. Cit. Not. 23, P.227

30 Molina Flores, Pedro, Control social de la adolescencia, México, 2007, Gudiño Ciseros, P. 13

31 Para los fines de este trabajo se ha considerado utilizar el curso de psicologia forense especializado en niñas, niños y adolescentes. Modulo I, Tema II, desarrollado por Bárbara Straccali. Oficina de Defensoría de los Derechos de la Infancia A.C., basado en el modelo constructivista, dado que, como lo señala la autora, cada teoría del desarrollo representa una ventana de abordaje, por lo tanto, no se acude a una teoría en especificó.

32 Curso de psicologia forense especializado en niñas, niños y adolescentes. Modulo I, Tema II, desarrollado por Bárbara Straccali. Oficina de Defensoría de los Derechos de la Infancia A.C.

33 Idem 
No es que, el adolescente no tenga la capacidad de enteder o comprender la conducta que realiza; es que, en el proceso, son más susceptibles a la invasión de lo emotivo por sobre lo racional y acaban pensando y actuando en un nivel concreto; por lo que, fácilmente se confunden, se sienten presionados, y reaccionan con mecanismos de omnipotencia e impulsividad. Es así que, la adolescencia es especialmente vulnerable a la irrupción de emociones, y atraviesa una etapa de desarrollo físico que la somete a fuertes cambios hormonales que, como es sabido, provoca labilidad emocional, emociones extremas, dificultades para lograr autocontrol, dificultades para pensar y planear objetivamente.34

Por la gran predominancia fuertes emociones (amores, odios, temores y dudas) con las que los jóvenes deben lidiar hace que éstas acaben venciendo a la razón. La inteligencia y habilidades adquiridas a esta altura del desarrollo deben estabilizarse antes de poder utilizarse objetiva y sistemáticamente. 35

\section{CONCLUSIONES}

En esta época, los niños se han visto inmersos en un mundo globalizado, en la que el avance en las tecnologías de acceso a la información y comunicación,36 redes sociales, les ha permitido tener acceso a imágenes explicitas e información concerniente a relaciones sexuales prematuras, violencia, adicciones, en las que la vida del delincuente se proyecta como exitosa; esto, antes de ser capaces de tomar desiciones racionales sin ser dominados por las emociones.

Es la estapa en la que se encuentran madurando mentalmente, formando el carácter, la personalidad, estableciendo límites, cuya imaginación en ocasiones es aterrizada en la realidad en la forma en la cual la concibieron, de modo que, sus actos aunque con discernimiento de lo prohibido sin criterio para Juzgar sobre lo endeble de la información y los modelos que toman como ejemplos, circunstancias que cuando concurren con familias disfuncionales, violencia familiar, pobreza, desigualdad en las oportunidades, falta de educación, abuso sexual, abandono, alcoholismo, drogadicción, prostitución, entre otros; los coloca en una situación de vulnerabilidad que en la mayoría de los casos los hace entrar en conflicto con la ley penal.

Por lo que, en efecto, era necesario un sistema especializado en justicia para adolescentes, en el que respondieran penalmente por sus conductas; pero, sin pasar por alto, las caracteristicas derivadas del desarrollo, pero sobre todo, en el que se preponderara conocer las causas que los llevaron a delinquir. Bajo tal contexto, resultaba necesario no sólo establecer la diferenciación en la edad y el dicernimiento como el Código de 1871, lo hacía, comparandolos con los "locos y sordomudos"; ni sólo considerarlos como objetos de protección y tutela, actuando en auxilio de la patria potestad, como en los modelos Tribunal de Menores y El Consejo Tutelar.

En efecto era necesario establecer la defensa social; pues resulta insoslayable, que algunos adolescentes participan en conductas delictivas de gran impacto social, como secuestros, extorciones, violaciones,

34 Idem.

35 Escenarios de la delincuencia organizada, 2012, en prensa. Castañer, Analía, anexo psicopedagógico del Protocolo para la atención de niños, niñas y adolescentes en prensa. Citado en curso de psicologia forense especializado en niñas, niños y adolescentes. Modulo I, Tema II, desarrollado por Bárbara Straccali. Oficina de Defensoría de los Derechos de la Infancia A.C.

36 Sobre la importancia del desarrollo tecnológico y la innovación, se recomienda: Martínez, G., Silva, F., Altamirano, M., y de la Torre, J. F. (2021). Desarrollo tecnológico e innovación en México. 3C Empresa. Investigación y pensamiento crítico, 10(1), 71-81. https://doi.org/10.17993/3cemp.2021.100145.71-81 
homicidios, forman parte de la delincuencia organizada entre otros.

Conductas respecto de las cuales pareciera demasiado benévolo el sistema, frente a conductas tan graves que parecieran no tener justificación y que merecieran castigos más severos.

Ello ha ocasionado que, la Justicia para Adolescentes, se conciba por la sociedad y aun entre los operadores del sistema, como una forma de solapar a este sector de la población, respecto de la cual la sociedad pide castigos más rigurosos para quienes consideran actúan y piensan como un adulto lo haría.

Empero, ahora sabemos que, no es así, que los adolescentes no es que no quieran, esque no pueden formular el pensamiento deductivo o racional y, si a caso lo alcanzaren son dominados por las emociones; de modo que, no es posible exigir a los adolescentes un comportamiento ajustado los modelos socialmente correctos, en la misma forma que un adulto lo haría.

Por lo tanto, debe quedar claro que, la inimputabilidad en estas personas no deriva del hecho de ser personas menores de dieciocho años; sino del proceso de crecimiento, por virtud del cual no pueden ejercer juicio sobre sus actos tal como un adulto lo haría, desde luego que, podrían haber excepciones, pero en lo general es lo que ocurre con este grupo de personas por lo que resulta indispensable, se insiste, conocer las causas que motivaron que el adolescente cometiera el delito.

Es oportuno, dado el estado en el que se encuentra el analisis, ejemplificar la nececidad de tener en consideración las caracteristica de una persona en desarrollo y conocer las causas generadoras del delito; a través del caso de un adolescente que estuvo sujeto al sistema integral de justicia de Tabasco; en los albores de la implementación de este sistema.

La peculiaridad de este caso, es que, este niño, no era la primera vez que robaba; sino que, había estado sujeto en cuatro ocasiones anteriores y la violencia comenzaba a hacerse presente.

Esto generaba que se cuestionara la eficacia del sistema y se fortaleciera la idea de benevolencia hacía los adolescnetes, pues en aquella época como en la actual el internamiento sólo procedia en los casos más graves y la conducta cometida por el adolescente no era considerada como tal por la ley.

Ello, generó la necesidad buscar jurídicamente una forma particular de trato para el adolescente; por lo que se revisaron los expedientes anteriores, con motivo de lo cual pudo conocerse que, en uno se sus ingresos al Centro de Internamiento, le fue practicado un dictamen psicologico en el que el adolescente narró que, desde los catorce años había tenido que abandonar su hogar dado el maltrato recibido por su madre y por las parejas que ella había tenido, pero sobre todo porque no le perdonaba que hubiese regalado a su hermanito de ocho años, el experto en psicologia asentó entre parentesis que el adolescente en ese punto partia en llanto incontenido; con motivo de lo cual, dormía en una lavadora de autos o donde pudiera realizarlo.

Este hallazgo confirma que, en efecto, las circunstancias que conducen a un adolescente a cometer delitos son muy diferentes a las que las generan en los adultos.

¿Cómo podría exigirse a este adolescente ajustarse a los modelos de conducta considerados correctos; si su propia madre lo había dañado en sus emociones y orillado a sobrevivir coexitiendo con los peligros de la calle? 
Este adolescente, pidió al impartidor de justicia permanecer en el Centro de Internamiento, pues en ese momento ya estaba habituado a las drogas y sabía que por sí mismo volvería a delinquir y que, por su propia voluntad no permanecería en un albergue o institución de asistencia social sin que escapara.

Una vez que se conocieron estas causas, el trato y las medidas que se tomaron se encaminaron exclusivamente a que superara sus afecciones tanto emocionales como en relación al consumo de drogas.

Por ello, es necesario entender que la especialidad en el proceso de justicia para adolescnetes no se constituye únicamente por la aplicación de los tratados internacionales y las leyes en materia de la niñez.

Mis queridos jóvenes:

Veo la luz de vuestros ojos,

la energía que emana de vuestros cuerpos

y la esperanza que impregna vuestras almas.

Sé que sois vosotros, y no yo, quienes levantaréis el futuro. Que sois vosotros, y no yo, rectificaréis nuestros errores y haréis suma y seguiréis con las cosas buenas de este mundo.

Nelson Mandela

\section{REFERENCIAS}

1. ALZATE PIEDRAHITA, María Victoria, "Concepciones e imágenes de la infancia" revista Colombiana, núm. 28, 2001. http://www.utp.edu.co/ chumanas/revistas/revistas/rev28/alzate.htm

2. ALVARADO MARTÍNEZ, Israel, et al, (coord.) La nueva justicia integral para adolescentes, México, Tribunal Superior de Justicia del Distrito Federal, 2009.

3. AZAOLA, Elena, "Posibilidades y límites de dos modelos de justicia para menores", en Memoria del Coloquio Multidisciplinario sobre Menores, Instituto de Investigaciones Jurídicas, Universidad Nacional Autónoma de México (UNAM), México, Cuadernos del Instituto, núm. 1, 1996, disponible en www.bibliojuridica.org.

4. BLANCO ESCANDÓN, Celia, Estudio Histórico y Comparado de la Legislación de Menores Infractores, Instituto de Investigaciones Jurídicas, UNAM, disponible en http://biblio.juridicas. unam.mx/libros/4/1968/7.pdf.

5. CASTILlO LÓPEZ, Juan Antonio, Justicia de Menores en México: El Desfase Institucional Jurídico, Porrúa, México, 2006.

6. Clavijero, Francisco Javier, "Historia Antigua de México", Sepan cuantos, México, Porrúa, 1982, pp. 202, 203. justicia_de_menores.pdf

7. CILLERO, Miguel, La responsabilidad Penal de Adolescentes y el interés del Niño: ¿complemento o contradicción? Ediciones del Signo: Editores del Puerto, Buenos Aires, 2004.

8. DEMAUSE, Lloyd, Historia de la infancia, España, Alianza Editorial, 1982.

9. Del Tribunal de Menores al Sistema Integral de Justicia para Adolescentes, Cuadernos de Jurisprudencia, número 4, julio 2009, disponible en https://www.scjn.gob.mx/libreria/Lists/ Catalogo_texto/DispForm.aspx?ID=165\&ContentTypeId=0x01006125D93BB9BF064893638E3 EA14AD86D.

10. ECHEVERRY LÓPEZ, Ovidio, "Situación, naturaleza y perspectiva del proyecto de convención sobre los derechos del niño", Derechos de la Niñez, Instituto de Investigaciones Jurídicas, México UNAM, 1990.

11. FADIMAN James y FRAGER Robert, Teorías de la Personalidad, traducción de Jesús Villamizar Herrera, Harla, México, 1979. 
12. FESTER C.B, Mary Carol Perrott, Principios de la Conducta, traducción de Roberto Helier, Trillas, México, 1977.

13. GARCÍA MÉNDEZ, Emilio, Infancia y adolescencia; de los derechos y la justicia, Doctrina Jurídica Contemporánea, México, UNICEF, Fontamara, 2001.

14. GARCÍA RAMÍREZ, Sergio, Cuestiones criminológicas y penales contemporáneas (estupefacientes y psicotrópicos, aborto, sanciones, menores infractores), México, Instituto Nacional de Ciencias Penales.

15.

16. Gardner, Martin, Understanding Juvenile Law, New York: Mathew Bender, 1997, pp. 183, citado en: Duce, Mauricio y Couso, Jaime, "El derecho a un juzgamiento especializado de los jóvenes infractores en el derecho comparado". Polit. crim. Vol. 7, núm. 13 Julio de 2012, pp. 1 - 73. [http:// www.politicacriminal.cl/Vol_07/n_13/Vol7N13A1.pdf

17. GONZÁLEZ DEL SOLAR, José, Delincuencia y derecho de menores. Aporte para una legislación integral, Ediciones Depalma, Buenos Aires, 1986.

18. GONZÁLEZ HERNÁNDEZ, Estela Guadalupe, et al, (eds), Justicia para adolescentes, México, Tribunal Superior de Justicia del Distrito Federal, 2008.

19. LIWSKI, Norberto Ignacio, "Hacia un sistema Integral de justicia y políticas acordes con el marco jurídico internacional," en Gutiérrez Contreras Juan Carlos (coord.), Derechos Humanos de los niños, niñas y adolescentes, Programa de Cooperación Sobre derechos Humanos de la Comisión Europea- Secretaria de Relaciones Exteriores, México, 2006.

20. MARTÍN LÓPEZ, María Teresa. "La responsabilidad penal de los menores”, Castilla, La Mancha, Cuenca, Edit. Universidad de 2001.

21. MANES Facundo y NIRO Mateo, Usar el cerebro, conocer nuestra mente para vivir mejor, Paidos, 2014, Argentina, 9na ed, p. 224.

22. Martínez, G., Silva, F., Altamirano, M., y de la Torre, J. F. (2021). Desarrollo tecnológico e innovación en México. 3C Empresa. Investigación y pensamiento crítico, 10(1), 71-81. https://doi. org/10.17993/3cemp.2021.100145.71-81

23. MOLINA FLORES, Pedro, Control social de la adolescencia, México, Gudiño Ciseros, 2007.

24. PAPALIA, Diane E., et al, Desarrollo Humano, traducción de José Francisco Javier Davila Martínez y María Elena Ortiz Salinas, 11 ed. McGraw-Hill, México, 2009.

25. PÉREZ SOSA, Artemio, Enfermería y Patología Psiquiátricas. México: Trillas, 1989.

26. RODRÍGUEZ MANZANERA, Luis, "El Derecho Internacional ante el Menor Infractor". Criminalia, México, año LVII, núm. 1, enero-abril 1992.

27. RODRÍGUEZ MANZANERA, Luís, Criminalidad de menores, $3^{\text {a }}$ ed., Porrúa, México, 2000.

28. ROSADO, Yordi, ¡Renuncio ¡ tengo un hijo adolescente ¡y no sé qué hacer;, Prisa Ediciones, México 2012.

29. SALDAÑA SERRANO, Javier, Derecho Natural, Tradición, Falacia Naturalista y Derechos Humanos, México, UNAM, 2012.

30. SÁNCHEZ CORDERO, Olga, Introducción a la interpretación del artículo 18 Constitucional, Tribunal Superior de Justicia del Distrito Federal, disponible en http://www.scjn.gob.mx/ conocelacorte/ministra/conferencia-menores-infractores-tsjdf-def.pdf -

31. SANZ DE LA GARZA, Joaquim Homs, Trastorno mental transitorio y drogas que inciden en la imputabilidad, España, J.M. Bosch Editor, S.L., 1996.

32. SHAFER, David R., Psicología del desarrollo, Infancia y Adolescencia, traducción de Jorge Alberto Velázquez Arellano, $5^{\text {a }}$ ed., México, 1999, International Thomson Editores.

33. SOSA CASTELLANOS, Josué, sintesis de la psicología general, $4^{\mathrm{a}}$ ed, Porrúa, México,1976.

34. Suprema Corte de Justicia de la Nación, La justicia de menores a la luz de los criterios del Poder Judicial de la Federación, México, SCJN, 2007.

35. VASCONCELOS MÉNDEZ, Rubén, La justicia para adolescentes en México, México, UNICEF - UNAM, 2009. p. 100.

36. VILLANUEVA CASTILLEJA, Ruth, Justicia en Menores Infractores, Delma, México, 2000.

37. VILLANUEVA CASTILLEJA, Ruth, La Justicia de Menores Infractores en la Reforma al Artículo 18 Constitucional, Porrúa, México, 2006.

38. VILLANUEVA CASTILLEJA, Ruth, Visión especializada del tratamiento para menores infractores, México, Porrúa, 2004.

39. Zaffaroni Eugenio Raúl, et al., Derecho penal: parte general, Porrúa, México, 2001. 